\title{
Computational study of unsteady mixed convection heat transfer of nanofluids in a 3D closed lid-driven cavity
}

\author{
Ali Khaleel Kareem ${ }^{\text {a, b,*, }}$, Shian Gao ${ }^{\text {a }}$ \\ ${ }^{\text {a }}$ Department of Engineering, University of Leicester, Leicester LE1 7RH, United Kingdom \\ ${ }^{\mathrm{b}}$ Engineering Department, University of Thi-Qar, 64001 Nassiriya, Iraq
}

\begin{abstract}
Mixed heat convection of three-dimensional unsteady flow of four different types of fluids in a double lid-driven enclosure is simulated by a two-phase mixture model in this project. The cubic cavity with moving isothermal sidewalls has uniform heat flux on the middle part of the bottom wall, and the other remaining walls forming the enclosure are adiabatic and stationary. The relevant parameters in the present research include Reynolds number Re (5000-30000), nanoparticle diameter (25nm-85nm), and nanoparticle volume fraction (0.00-0.08). In general, remarkable effects on the heat transfer and fluid patterns are observed by using nanofluids in comparison to the conventional fluid. Different types of nanofluids or different diameters of nanoparticles can make pronounced changes in the heat convection ratio. In addition, increasing in either volume fraction of nanoparticles or Reynolds number leads to increasing in the Nusselt number, fluctuation kinetic energy and root mean square velocity of the fluid in the domain. It is also found that both URANS and LES methods have shown good performance in dealing with unsteady flow conducted in this project. However, the comparisons have elucidated clearly the advantages of the LES approach in predicting more detailed heat and flow structures.
\end{abstract}

Keywords: Nanofluid, Lid-driven cavity, Mixed convection, Turbulent flow, Unsteady simulation, URANS, LES.

\footnotetext{
*Corresponding author at: Department of Engineering, University of Leicester, Leicester LE1 7RH, United Kingdom. Tel.: +44 (0)116 252 2874; fax: +44 (0)116 2522525.

Email address: akkak2@1e.ac.uk, alikhalee117@yahoo.com (A.K. Kareem).
} 


\section{Introduction}

In the last few years there has been a growing interest in nanofluids acting as a new heat transfer working fluid instead of conventional fluid such as oil or water. Adding nanoparticles into base fluids plays vital roles in the thermal properties of heat transfer fluids. The main concern of mixing metal micro-particles within base fluids can be traced back to Maxwell's study decades ago but not without major drawbacks such as high pressure drop. However, these disadvantages have been solved perfectly over few years back through reducing the particles size to the nanometer range. Besides, considerable attention has been paid to the research on these fluids in mixed convection of lid-driven cavity, due to their extensive industrial and engineering applications in, for instance, electronic cooling, solar collectors, coating and mixing, air conditioning and air cooling systems [1].

\begin{tabular}{|c|c|c|c|}
\hline \multicolumn{4}{|c|}{ Nomenclature } \\
\hline A & aspect Ratio & $\mathrm{W}$ & dimensionless velocity component at \\
\hline $\mathrm{Au}$ & gold & & z-direction \\
\hline $\mathrm{C}$ & Smagorinsky coefficient & $l$ & length of the heat source (m) \\
\hline $\mathrm{C}_{\mathrm{P}}$ & specific heat at constant pressure & $\begin{array}{l}x \\
x\end{array}$ & distance along the x-coordinate \\
\hline $\mathrm{CuO}$ & copper oxide & $x$ & $\mathrm{x}$-coordinate $(\mathrm{x} / \mathrm{L})$ \\
\hline $\mathrm{CO}_{2}$ & carbon dioxide & Y & distance along the non-dimensional \\
\hline CFL & Courant-Friedrichs-Lewy number & & $y$-coordinate $(y / H)$ \\
\hline E & $\begin{array}{l}\text { dimensionless length of the heat } \\
\text { source }(l / \mathrm{L})\end{array}$ & $\mathrm{Z}$ & $\begin{array}{l}\text { distance along the non-dimensional } \\
\mathrm{z} \text {-coordinate }(\mathrm{z} / \mathrm{D})\end{array}$ \\
\hline FVM & finite volume method & $\mathrm{ZnO}$ & zinc oxide \\
\hline Gr & Grashof number $\left(\mathrm{g} \beta_{\mathrm{m}} \Delta \mathrm{TW} / \mathrm{v}_{\mathrm{m}}^{2}\right)$ & & \\
\hline $\mathrm{h}$ & $\begin{array}{l}\text { convective heat transfer coefficient } \\
\left(\mathrm{W} / \mathrm{m}^{2} \mathrm{~K}\right)\end{array}$ & \multicolumn{2}{|c|}{ Greek symbols } \\
\hline $\begin{array}{l}\mathrm{Ha} \\
\mathrm{k}\end{array}$ & $\begin{array}{l}\text { Hartmann number } \\
\text { turbulent kinetic energy }\left(\mathrm{m}^{2} / \mathrm{s}^{2}\right)\end{array}$ & $\beta$ & $\begin{array}{l}\text { volumetric coefficient of thermal } \\
\text { expansion }(1 / \mathrm{K})\end{array}$ \\
\hline $\mathrm{L}$ & width of the cavity $(\mathrm{m})$ & $\mu$ & dynamic viscosity of the fluid $(\mathrm{Pa} / \mathrm{s})$ \\
\hline MHD & magnetohydrodynamics & $v$ & kinematic viscosity of the fluid \\
\hline $\begin{array}{l}\text { Nu } \\
\text { Pr }\end{array}$ & $\begin{array}{l}\text { Nusselt number } \\
\text { Prandtl number }\left(v_{m} / \alpha_{m}\right)\end{array}$ & & 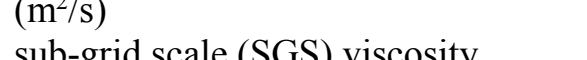 \\
\hline q" & $\begin{array}{l}\text { PrandtI number }\left(v_{\mathrm{m}} / \alpha_{\mathrm{m}}\right) \\
\text { heat flux }\left(\mathrm{W} / \mathrm{m}^{2}\right)\end{array}$ & $\begin{array}{l}v_{s g s} \\
\theta\end{array}$ & $\begin{array}{l}\text { sub-grid scale (SGS) viscosity } \\
\text { dimensionless temperature }\end{array}$ \\
\hline $\mathrm{Ra}$ & Rayleigh number (Gr Pr) & $\rho$ & density of the fluid $\left(\mathrm{kg} / \mathrm{m}^{3}\right)$ \\
\hline $\operatorname{Re}$ & Reynolds number $\left(\mathrm{U}_{0, \mathrm{~m}} \mathrm{~W} / \mathrm{v}_{\mathrm{m}}\right)$ & $\varepsilon$ & dissipation rate of turbulent kinetic \\
\hline $\mathrm{Ri}$ & Richardson number $\left(\mathrm{Gr} / \mathrm{Re}^{2}\right)$ & & energy $\left(\mathrm{m}^{2} / \mathrm{s}^{3}\right)$ \\
\hline $\mathrm{SiO}_{2}$ & silicon dioxide & $\delta_{i j}$ & Kronecker's delta \\
\hline$\overline{\mathrm{S}}_{\mathrm{ij}}$ & $\begin{array}{l}\text { large-scale strain rate tensor for grid- } \\
\text { filter }\end{array}$ & $\bar{\Delta}$ & grid-filter width \\
\hline $\mathrm{T}$ & $\begin{array}{l}\text { filter } \\
\text { temperature of the fluid }(\mathrm{K})\end{array}$ & $\tau_{i j}$ & subgrid-scale (SGS) stress tensor \\
\hline t & time & Subs & \\
\hline $\begin{array}{l}\mathrm{TiO}_{2} \\
\mathrm{u}\end{array}$ & $\begin{array}{l}\text { titanium dioxide } \\
\text { velocity component at } \mathrm{x} \text {-direction } \\
(\mathrm{m} / \mathrm{s})\end{array}$ & $\begin{array}{l}\text { av } \\
b \\
b f\end{array}$ & $\begin{array}{l}\text { average value } \\
\text { buoyancy } \\
\text { base fluid }\end{array}$ \\
\hline $\mathrm{U}$ & $\begin{array}{l}\text { dimensionless velocity component at } \\
\mathrm{x} \text {-direction }\end{array}$ & C & value of cold temperature \\
\hline $\mathrm{U}_{0}$ & lid velocity $(\mathrm{m} / \mathrm{s})$ & $\mathrm{H}$ & value of hot temperature \\
\hline $\mathrm{v}$ & $\begin{array}{l}\text { velocity component at y-direction } \\
(\mathrm{m} / \mathrm{s})\end{array}$ & $\mathrm{m}$ & mixture \\
\hline
\end{tabular}




\begin{tabular}{|llll|}
\hline $\mathrm{V}$ dimensionless velocity component at & $\mathrm{nf}$ & nanofluid \\
& $\mathrm{np}$ & nanoparticles \\
& $\mathrm{rms}$ & root mean square \\
& $\mathrm{s}$ & source \\
& $\mathrm{sgs}$ & sub-grid scale \\
& $\mathrm{t}$ & turbulent \\
\hline
\end{tabular}

In recent years, research on both nanofluids and mixed convection of lid-driven cavity has become especially popular, among the notable investigations are those by Abu-Nada and Chamkha [2], Goodarzi, et al. [3], Kareem, et al. [4]and Billah, et al. [5]. In the literature, several theories and studies have been proposed to explain the conditions for steady or unsteady laminar flow problems in lid-driven cavity. One of the first examples of laminar case is an unsteady mixed convection heat transfer in a $2 \mathrm{D}$ lid-driven inclined triangular cavity filled with $\mathrm{Cu}-\mathrm{H}_{2} \mathrm{O}$, investigated numerically by Billah, et al. [5]. The most important objective in their study was the investigation of unsteady heat transfer enhancement of nanofluids within the enclosure. It was concluded that using nanofluids leads to the improvement in heat transfer coefficient. Abu-Nada and Chamkha [2] investigated numerically a 2D mixed convection flow in enclosure with moving top wall and wavy bottom wall, filled with nanofluids. The aim was to find the steady laminar mixed convection of $\mathrm{CuO}-\mathrm{H}_{2} \mathrm{O}$ within the lid-driven wavy cavity. It was proved that at the considered Richardson number (Ri) the nanoparticles have a significant effect on the heat transfer enhancement as well as the wavy bottom wall geometry ratios. Back to 2010 Abu-Nada and Chamkha [6] also studied numerically a steady laminar mixed convection flow in a 2D lid-driven inclined square enclosure filled with nanofluid $\mathrm{Al}_{2} \mathrm{O}_{3}-\mathrm{H}_{2} \mathrm{O}$. They studied the effects of Richardson number, nanoparticle volume fraction and enclosure inclination angle on the heat transfer characteristics. It was concluded that the heat transfer mechanisms and the flow characteristics inside the cavity were strongly dependent on the Richardson number. Moreover, the significant heat transfer enhancement could be obtained due to the presence of nanoparticles and that was accentuated by inclination of the enclosure at moderate and large Richardson numbers. The mixed convection in a liddriven triangular enclosure filled with $\mathrm{Al}_{2} \mathrm{O}_{3}-\mathrm{H}_{2} \mathrm{O}$ was investigated numerically by Ghasemi and Aminossadati [7]. They examined the effects of pertinent parameters such as Richardson number, solid volume fraction, and the direction of the vertical sliding wall motion on the thermal performance of the enclosure. It was reported that the addition of nanoparticles showed an improvement in the heat transfer rate of the enclosure. The direction of the sliding wall motion proved to affect the flow and temperature distribution within the enclosure and the heat transfer rate. For all values of the Richardson number, the downward sliding wall proved a higher heat transfer rate compared to the upward sliding wall. For both upward and downward sliding walls with a constant solid volume fraction, decreasing the Richardson number resulted in a higher heat transfer rate due to strengthening of flow circulation by the effects of sliding wall motion.

However, only a few researchers have paid attention to the two-phase mixture model with nanofluids. Alinia, et al. [8] studied numerically a mixed convection heat transfer of nanofluids within an inclined two sides moving wall cavity by using two-phase mixture model. Analysing the effects of volume fraction of nanoparticles and the inclination angle on the thermal characteristics at Reynolds number from 0.01 to 100 was their main objective. It was observed that considerable improvement on heat transfer was made due to increasing the concentration of the nanoparticles, and that inclination angle affected the heat transfer especially with increasing the Richardson number. Goodarzi, et al. [3] 
examined numerically both laminar and turbulent mixed convection heat transfer of nanofluids inside a 2D shallow enclosure. Two different values of Grashof number $\mathrm{Gr}=10^{5}$ (laminar flow) and $10^{10}$ (turbulent flow) with different values of Ri and different nanoparticle concentration were studied. It was observed that increasing nanoparticle fraction leads to the enhancement of the heat transfer ratio and Nusselt number $(\mathrm{Nu})$. In addition, turbulent kinetic energy, turbulence intensity, wall shear stress and skin friction were also affected by nanoparticle concentration.

Considerable investigations have been undertaken on the conventional fluids compared to the nanofluids. The present authors [9] have earlier completed numerically a study of unsteady mixed convection heat transfer of water within a three dimensional lid-driven enclosure. It was demonstrated clearly the ability of both URANS and LES models in dealing with turbulent flow structures and heat distributions. Aydin and Yang [10] studied numerically the transport mechanisms of laminar mixed convection of air in a shear- and buoyancy-driven cavity that has a locally heated lower wall and moving cooled sidewalls. Localized heating was simulated by a centrally located heat source on the bottom wall and different values of the dimensionless heat source length, $\varepsilon$. It was concluded that the mixed convection region with comparable shear and buoyancy forces was more effective for $0.5 \leq \mathrm{Gr} / \operatorname{Re}^{2} \leq 2$. The other remaining left and right parts of the mixed convection region were with weak buoyancy and strong buoyancy, respectively. The effective range of the mixed convection regime becomes larger with increasing value of $\varepsilon$. Aydm [11] investigated numerically the transport mechanisms of laminar combined convection air flow in a shear- and buoyancy-driven cavity. The interaction of the forced convection with the natural convection was studied. Two orientations of thermal boundary conditions at the cavity walls were considered in order to simulate the aiding and opposing buoyancy mechanisms. It was concluded that with increasing value of Richardson number, three different heat transport regimes were defined as follows: the forced convection, the mixed convection and the natural convection. In addition, the mixed convection range of Richardson number for the opposing-buoyancy case was wider than that of the aiding-buoyancy case. Three-dimensional numerical simulation of flow and heat transfer in a lid-driven cavity that filled with a stably stratified fluid was investigated by Mohamad and Viskanta [12]. The effects of sliding lid on the flow and thermal structures in the shallow cavity were studied. It was concluded that increasing the retarding force and the buoyancy force prevents the return flow from penetrating to the bottom of the cavity. Therefore, the fluid is recirculated at the upper portion of the cavity. The upper recirculation induces shear on the lower fluid layer and forms another weak recirculated flow region. Admittedly, the rate of heat transfer increases as Richardson number decreases or the Reynolds number increases. The maximum local heat transfer rate occurs at the start of the sliding lid. Return flow impingement on the bottom of the cavity also increases the rate of heat transfer locally at the region of impingement. Three-dimensional flow structures and the companion heat transfer rates in a double lid-driven cubic cavity, heated from the top and cooled from the below, were studied by Ouertatani, et al. [13]. Numerical solutions were generated for representative combinations of the controlling Reynolds number and Richardson number. Typical sets of streamlines and isotherms were presented to analyze the tortuous circulatory flow patterns setup by the competition between the forced flow created by the double driven walls and the buoyancy force of the fluid. It was observed that when $\mathrm{Ri}$ was small and Re was large, the flow was basically carried through or using the lids movement. In this case the mechanically driven convection was or became dominant. The mixed convection heat transfer in a two-dimensional enclosure trapezoidal cavity with constant heat flux at the heated bottom wall was studied numerically by Mamun, et al. [14]. The isothermal top wall of the cavity is moved in 
the horizontal direction. The effects of the inclination angle of the side walls, Ri number, Re number, aspect ratio and the rotational angle of the cavity on mixed convection flow were presented. It was concluded that the optimum configuration of the trapezoidal enclosure obtained at inclination angle $=$ $45^{\circ}$. As Ri number increases consequently the $\mathrm{Nu}_{\text {av }}$ increases accordingly at all aspect ratios. As the aspect ratio increases from 0.5 to 2.0 , the heat transfer rate increases. The direction of the motion of the lid also affects the heat transfer phenomena. Aiding flow condition always gives better heat transfer rate than opposing flow condition.

This research is a continuation of the earlier work published by the current authors [9]. In the previous paper the working fluid within the enclosure is a conventional fluid (water), unlike the current ones which focus on nanofluids besides pure water. The current work aims to address several fundamental issues; 1) it is important to have better understanding of two-phase mixture nanofluids within 3D geometry; 2) it is crucial to investigate the effects of different types of nanoparticles and their concentration and diameter size; 3 ) it is fundamentally essential to predict accurately the turbulent flow and heat distribution details inside the cavity.

\section{Methodology}

It is well known that the Computational Fluid Dynamics (CFD) approach is a useful design tool, especially in design optimization, process optimization and parametric study. The current investigations employ the commercial CFD code ANSYSCFLUENT (version R15.0) [15] to solve the governing equations of heat and fluid flow, based on the finite volume method (FVM). Both the Unsteady Reynolds-Averaged Navier-Stokes (URANS) and Large Eddy Simulation (LES) methods are applied to the two-phase mixture nanofluids inside the cavity. The thermos-physical property formulas for the nanofluids mixture are introduced into the software via User Defined Functions (UDFs). The popular SIMPLE procedure is utilized for dealing with the pressure-velocity coupling equations, and the QUICK scheme is applied to the convection terms of the momentum and energy equations, while the implicit second order scheme is used for the time evaluation terms. The simulation results are concluded once the iteration residuals for all the required parameters are below $10^{-6}$.

\subsection{Physical model and boundary conditions}

A schematic configuration under the current study in this paper with geometry parameters and main boundary conditions is shown in Fig. 1. Both sidewalls of the cavity are lidding downward with a constant velocity and fixed low temperature. The center part of the bottom wall $(l)$ is heated at a fixed value of heat flux, while the remaining parts of the bottom wall, the top wall, the front and back walls of the geometry are all adiabatic walls. 


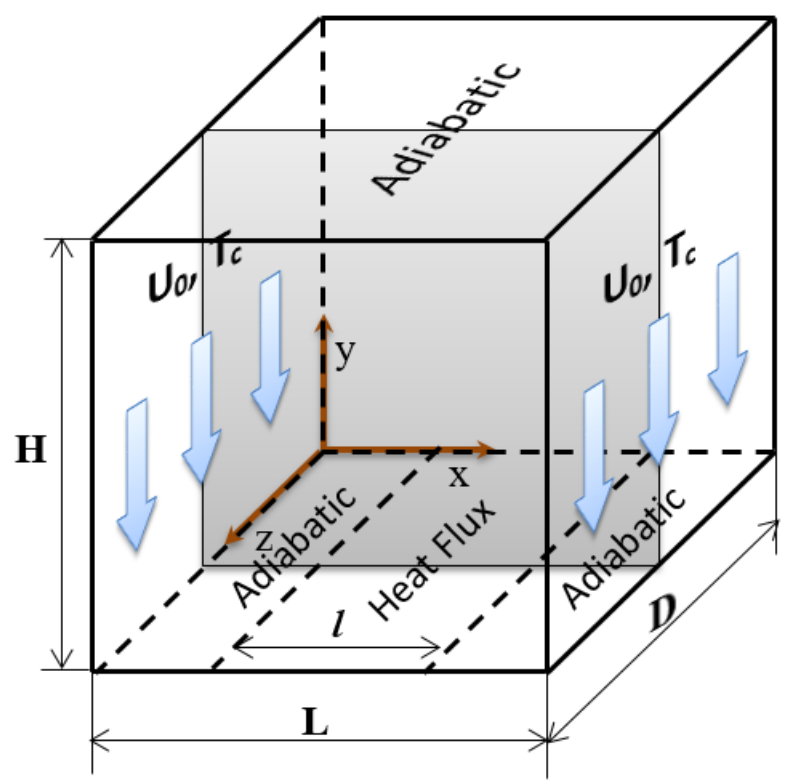

Fig. 1. Schematic diagram of the cubic lid-driven cavity

The appropriate boundary conditions for the current problems are:

Top wall: $\theta=0, \mathrm{U}=\mathrm{V}=\mathrm{W}=0$

Front wall: $\theta=0, U=V=W=0$

Rear wall: $\theta=0, \mathrm{U}=\mathrm{V}=\mathrm{W}=0$

Bottom wall: $\quad \frac{\partial \theta}{\partial \mathrm{Y}}=\left\{\begin{aligned} 0, & \text { for } 0<X<(1-E) / 2 \\ -1, & \text { for }(1-\mathrm{E}) / 2 \leq \mathrm{X} \leq(1+\mathrm{E}) / 2 \\ 0, & \text { for }(1+\mathrm{E}) / 2<X<1\end{aligned}\right\}$

- Right and left walls: $\theta=0, \mathrm{U}=0, \mathrm{~V}=-1, \mathrm{~W}=0$

where $\theta$ is the dimensionless temperature, and the condition $\partial \theta / \partial \mathrm{Y}=-1$ for $(1-\mathrm{E}) / 2 \leq \mathrm{X} \leq(1+$ E) $/ 2$ at the bottom wall arises due to the constant heat flux, q".

The local and average Nusselt numbers are defined respectively as:

$\mathrm{Nu}_{\text {Local }}=\frac{\mathrm{h}_{\mathrm{x}}}{\mathrm{k}}=\frac{1}{\theta_{\mathrm{s}}(\mathrm{X})}$

$\mathrm{Nu}_{\mathrm{av}}=\frac{\overline{\mathrm{h}}}{\mathrm{k}}=\frac{1}{\mathrm{E}} \int_{0}^{\mathrm{E}} \frac{1}{\theta_{\mathrm{s}}(\mathrm{X})} \mathrm{dX}$

where $\theta_{\mathrm{s}}(\mathrm{X})$ refers to the local dimensionless temperature, $\mathrm{k}$ represents the thermal conductivity, $\mathrm{h}_{\mathrm{x}}$ and $\overline{\mathrm{h}}$ are the heat transfer coefficient on $\mathrm{x}$-axis and the average heat transfer coefficient, respectively. 


\subsection{Governing equations}

A single fluid multiphase model i.e. the mixture model is utilized in this work. Subsequently, the mixture's continuity, momentum and energy are involved with Boussinesq approximation for the density in the present investigation. Based on Goodarzi, et al. [3], the governing equations can be written for three-dimensional flow in unsteady state:

Continuity equation:

$\frac{\partial \rho_{m}}{\partial t}+\frac{\partial u_{i, m}}{\partial x_{i}}=0$

Momentum equation:

$\frac{\partial u_{i, m}}{\partial t}+\frac{\partial\left(u_{j, m} u_{i, m}\right)}{\partial x_{j}}=-\frac{\partial P_{m}}{\partial x_{i}}+\frac{1}{R e}\left(\frac{\partial^{2} u_{i, m}}{\partial x_{i} \partial x_{i}}\right)+\frac{G r}{R e^{2}} \theta$

Energy equation:

$\frac{\partial(\theta)}{\partial t}+\frac{\partial\left(u_{j, m} \theta\right)}{\partial x_{i}}=\frac{1}{R e P r}\left(\frac{\partial^{2} \theta}{\partial x_{i} \partial x_{i}}\right)$

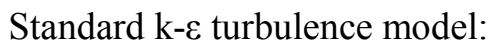

The turbulent kinetic energy $(\mathrm{k})$ and the dissipation rate $(\varepsilon)$ are written in Cartesian coordinates $(i, j$, k) as shown below [16].

$\frac{\partial}{\partial t}(\rho k)+\frac{\partial}{\partial x_{i}}\left(\rho k u_{i, m}\right)=\frac{\partial}{\partial x_{j}}\left[\left(\mu_{m}+\frac{\mu_{t, m}}{\sigma_{k}}\right) \frac{\partial k}{\partial x_{j}}\right]+P_{k, m}+P_{b, m}-\rho \varepsilon_{m}+S_{k, m}$

$\frac{\partial}{\partial t}(\rho \varepsilon)+\frac{\partial}{\partial x_{i}}\left(\rho \varepsilon u_{i, m}\right)=\frac{\partial}{\partial x_{j}}\left[\left(\mu_{m}+\frac{\mu_{t, m}}{\sigma_{\varepsilon}}\right) \frac{\partial k}{\partial x_{j}}\right]+C_{1 \varepsilon} \frac{\varepsilon}{k}\left(P_{k, m}+C_{3 \varepsilon} P_{b, m}\right)-C_{2 \varepsilon} \rho \frac{\varepsilon^{2}}{k}+S_{\varepsilon, m}$

where the user-defined source terms $\mathrm{S}_{\mathrm{k}}$ and $\mathrm{S}_{\varepsilon,}$ are equal to zero.

Turbulent viscosity: $\quad \mu_{t, m}=\rho C_{\mu} \frac{k^{2}}{\varepsilon}$

Production of k:

$$
P_{k, m}=-\rho \overline{u_{i, m}^{\prime} u_{j, m}^{\prime}} \frac{\partial u_{j}}{\partial x_{i}}
$$

Effect of buoyancy:

$$
P_{b, m}=\beta g_{i} \frac{\mu_{t, m}}{P r_{t}} \frac{\partial T}{\partial x_{i}}
$$

where $\mathrm{C}_{1 \varepsilon}, \mathrm{C}_{2 \varepsilon}$ and $\mathrm{C}_{3 \varepsilon}$ are model constants.

The LES sub-grid scale model of Smagorinsky-Lilly is given by [17]: 
$\tau_{i j}-\frac{\delta_{i j}}{3} \tau_{k k}=-2 v_{s g s} \bar{S}_{i j}=-2 C \bar{\Delta}^{2}|\bar{S}| \bar{S}_{i j}=-2 C \beta_{i j}$

where

$\beta_{i j}=-\bar{\Delta}^{2}|\bar{S}| \bar{S}_{i j}$

$\bar{S}_{i j}=\frac{1}{2}\left(\frac{\partial \bar{u}_{i}}{\partial x_{j}}+\frac{\partial \bar{u}_{j}}{\partial x_{i}}\right)$

$\bar{\Delta}=\left(\bar{\Delta}_{x} \bar{\Delta}_{y} \bar{\Delta}_{z}\right)^{\frac{1}{3}}$

$|\bar{S}|=\left(2 \bar{S}_{i j} \bar{S}_{i j}\right)^{\frac{1}{2}}$

\subsection{Thermo-physical properties of nanofluids}

The thermo-physical properties of the base fluid and nanoparticle types are presented in Table 1. The nanofluid being used is a mixture of water (base fluid) with either Silicon Dioxide, Copper or Silver nanoparticles. Basically, the required properties for this work are density, heat capacity, effective thermal conductivity, effective dynamic viscosity and thermal expansion.

Table 1

Thermo-physical properties of water and nanoparticles [18].

\begin{tabular}{llllll}
\hline & $\rho\left(\mathrm{kg} / \mathrm{m}^{3}\right)$ & $\mathrm{C}_{\mathrm{p}}(\mathrm{J} / \mathrm{kg} . \mathrm{K})$ & $\mathrm{k}(\mathrm{W} / \mathrm{m} . \mathrm{K})$ & $\mu\left(\mathrm{Ns} / \mathrm{m}^{2}\right)$ & $\beta \times 10^{-5}\left(\mathrm{~K}^{-1}\right)$ \\
\hline Pure Water $\left(\mathrm{H}_{2} \mathrm{O}\right)$ & 996.5 & 4181 & 0.613 & 0.0001 & 21 \\
\hline Silicon Dioxide $\left(\mathrm{SiO}_{2}\right)$ & 3970 & 765 & 36 & - & 0.63 \\
\hline Copper $(\mathrm{CuO})$ & 6500 & 533 & 17.65 & - & 0.85 \\
\hline Zinc Oxide $(\mathrm{ZnO})$ & 5600 & 495.2 & 13 & - & 0.72 \\
\hline
\end{tabular}

The density and heat capacity are calculated as stated by Ghasemi and Aminossadati [19] as shown in equation (16) and (17):

$$
\begin{aligned}
& \rho_{m}=(1-\phi) \rho_{b f}+\phi \rho_{n p} \\
& \left(\rho C_{p}\right)_{m}=(1-\phi)\left(\rho C_{p}\right)_{b f}+\phi\left(\rho C_{p}\right)_{n p}
\end{aligned}
$$


The effective thermal conductivity of the nanofluid by Vajjha, et al. [20] is written below:

$$
\begin{aligned}
& k_{\text {eff }}=k_{\text {Static }}+k_{\text {Brownian }} \\
& k_{\text {Static }}=k_{b f}\left[\frac{\left(k_{n p}+2 k_{b f}\right)-2 \phi\left(k_{b f}-k_{n p}\right)}{\left(k_{n p}+2 k_{b f}\right)+\phi\left(k_{b f}+k_{n p}\right)}\right] \\
& k_{\text {Brownian }}=5 \times 10^{4} \beta \phi \rho_{f} \mathrm{C}_{\mathrm{p}, \mathrm{f}} \sqrt{\frac{\mathrm{k} \mathrm{T}}{2 \rho_{\mathrm{np}} \mathrm{R}_{\mathrm{np}}}} \cdot f(T, \phi) \\
& \text { where Boltzmann constant is: } \mathrm{k}=103807 \times 10^{-23} \\
& f(\mathrm{~T}, \phi)=\left(2.8217 \times 10^{-2} \phi+3.917 \times 10^{-3}\right)\left(\frac{\mathrm{T}}{\mathrm{T}_{0}}\right) \\
& \quad+\left(-3.0699 \times 10^{-2} \phi-3.91123 \times 10^{-3}\right)
\end{aligned}
$$

where $\mathrm{T}$ is the reference temperature, $273 \mathrm{~K}$.

\section{Table 2}

the values of $\beta$ for different particles at temperature between 298 and 363k [21, 22].

\begin{tabular}{lll}
\hline Nanoparticlers types & $\beta$ & Volume fraction \\
\hline Copper $(\mathrm{CuO})$ & $\beta=9.881(100 \phi)^{-0.9446}$ & $1 \% \leq \phi \leq 6 \%$ \\
Zinc Oxide $(\mathrm{ZnO})$ & $\beta=8.4407(100 \phi)^{-1.07304}$ & $1 \% \leq \phi \leq 7 \%$ \\
Silicon Dioxide $\left(\mathrm{SiO}_{2}\right)$ & $\beta=1.9526(100 \phi)^{-1.4594}$ & $1 \% \leq \phi \leq 10 \%$ \\
\hline
\end{tabular}

The effective dynamic viscosity of the nanofluid by Corcione [23]can be calculated by using the equation below:

$$
\frac{\mu_{e f f}}{\mu_{b f}}=\frac{1}{1-34.87\left(\frac{d_{e f f}}{d_{b f}}\right)^{-0.3} \phi^{1.03}}
$$

The equivalent diameter of the base fluid molecule can be calculated by using the equation below: 
$d_{b f}=\left[\frac{6 M}{N \pi \rho_{b f}}\right]^{\frac{1}{3}}$

where:

$M$ : Molecular weight of the base fluid.

$N$ : Avogadro number $=6.022 \times 10^{23} \mathrm{~mol}^{-1}$.

Finally, the thermal expansion of the nanofluid stated by Ghasemi and Aminossadati [19] is given below:

$(\rho \beta)_{m}=(1-\phi)(\rho \beta)_{b f}+\phi(\rho \beta)_{n p}$

\subsection{Numerical procedure validation}

In this section, the numerical results from the current CFD model are compared with the available results from four journal papers in literature. Firstly, as seen in Fig. 2 and Fig. 3, two different validations of the URANS modelling are made against the results of Sharif [24], who studied a mixed convection heat transfer in a lid-driven rectangular enclosure, and against the outcomes of Chen and Cheng [25], who conducted an experimental study of mixed convection of air inside an arc-shape enclosure with driven top wall. It can be observed that excellent agreements have been achieved between the current CFD model and the previously published results. Secondly, the validation of two-phase mixture model of nanofluids has been completed, as displayed in Fig. 4, that the current predictions for the average Nusselt number have agreed very well with those obtained by Alinia, et al. [8]. Moreover, their research was about using the two-phase mixture model of nanofluids within a two sided lid driven enclosure. Finally, as shown in Fig. 5, the validation of LES model is found to agree nicely with the experimental research that was carried out by Prasad and Koseff [26]. Obviously, the present simulation results from the four cases have all shown great agreements with those from the previous research. Therefore, these validations have provided strong confidence that the current numerical solver is ready to run the new simulations. 


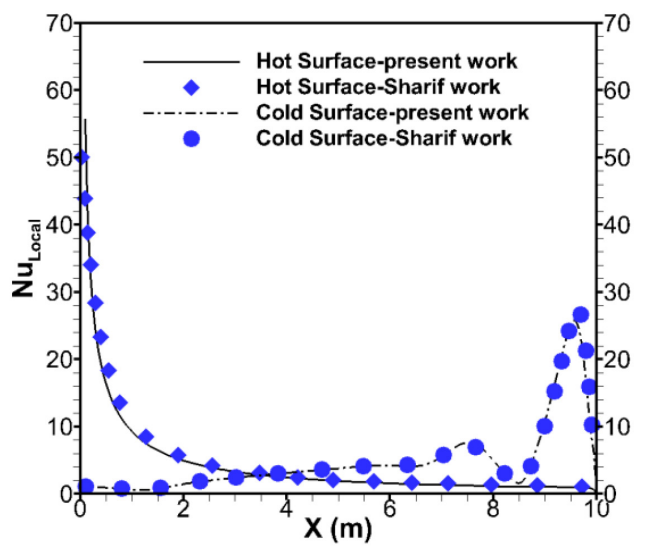

a) $\mathrm{Ri}=0.1$

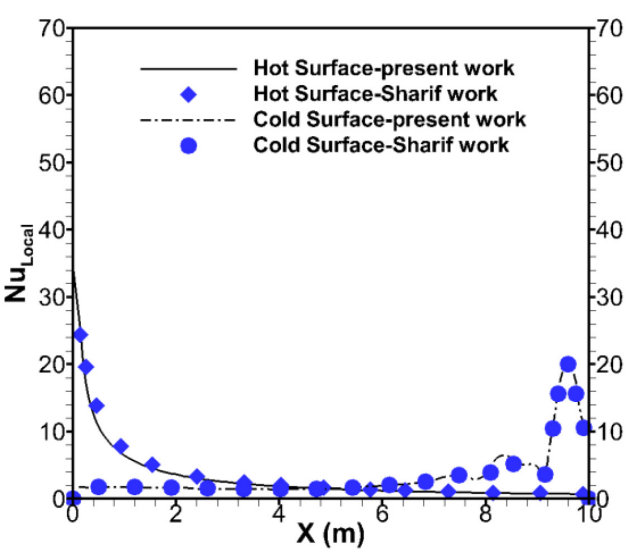

b) $\mathrm{Ri}=1$

Fig. 2. Comparison of the present work of the local Nusselt number with Sharif [24] for both cold and hot walls.

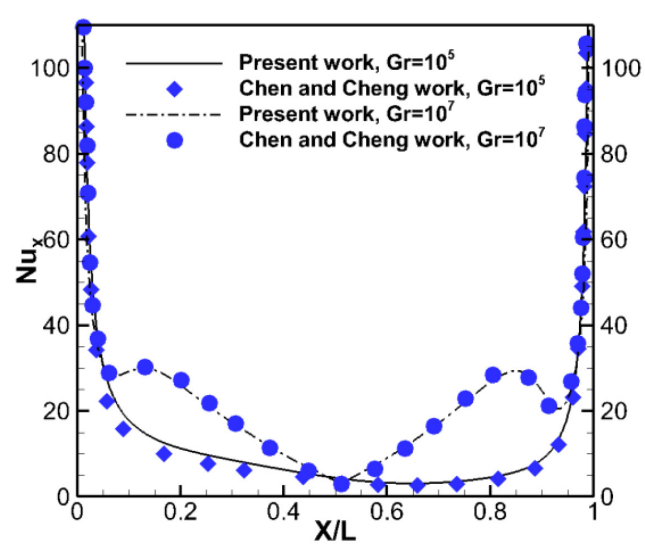

Fig. 3. Comparison of the present work of the local Nussle number with Chen and Cheng [25].

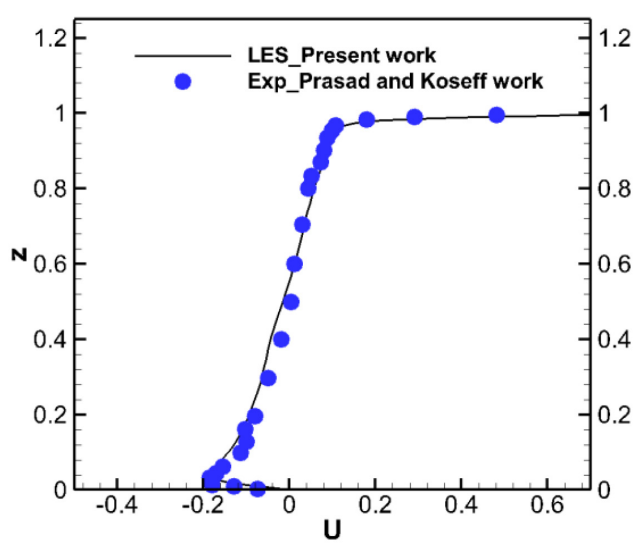

a) Right velocity

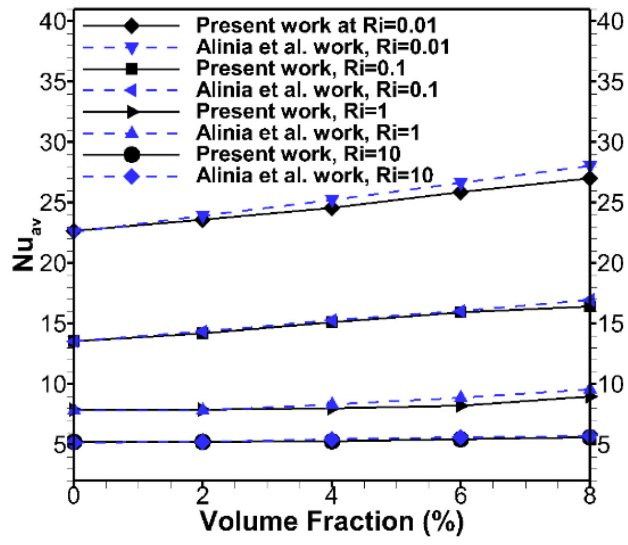

Fig. 4. Comparison of the present work of the average Nusselt number with Alinia, et al. [8].

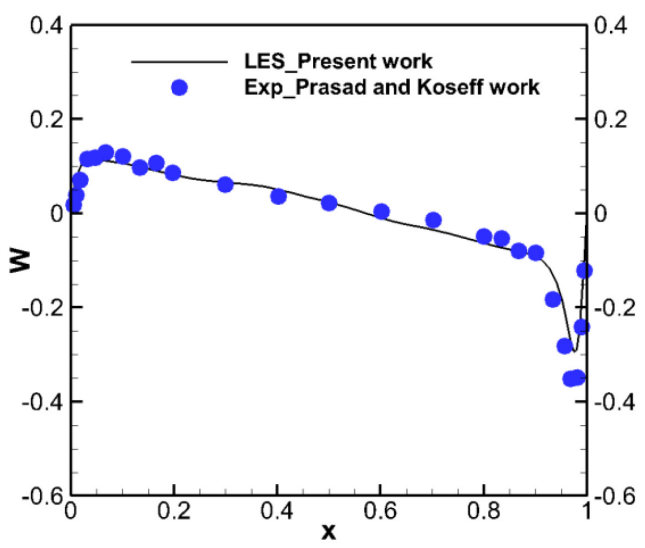

b) Left velocity

Fig. 5. Mean velocity profiles comparison of present LES work with Prasad and Koseff [26] at $\mathrm{Re}=$ 10000. 


\subsection{Grid independence test}

The computational domain was discretised by using structured and non-uniform meshes with more refined mesh close to the walls. The grid independence test was carried out for unsteady RANS modelling through using the standard $\mathrm{k}-\varepsilon$ model at constant values of $\mathrm{Re}=5000, \mathrm{Ri}=1$, and $\operatorname{Pr}=0.7$, and the convergence criterion is fixed, equal to $10^{-6}$ for all the equations. Five different grid numbers, $120000,410625,980000,1699200$ and 1921875, are tested in this study at non-dimensional time step equal to 0.0001 , with dimensionless wall distance, $\mathrm{y}^{+} \approx 1$ and Courant-Friedrichs-Lewy number, CFL $\approx 0.3$. It can be seen from Fig. 6 that the grid independence test is achieved with the last two node numbers. Therefore, the grid number 1699200 is selected in the present work to obtain the high quality simulation at reasonable computational cost.

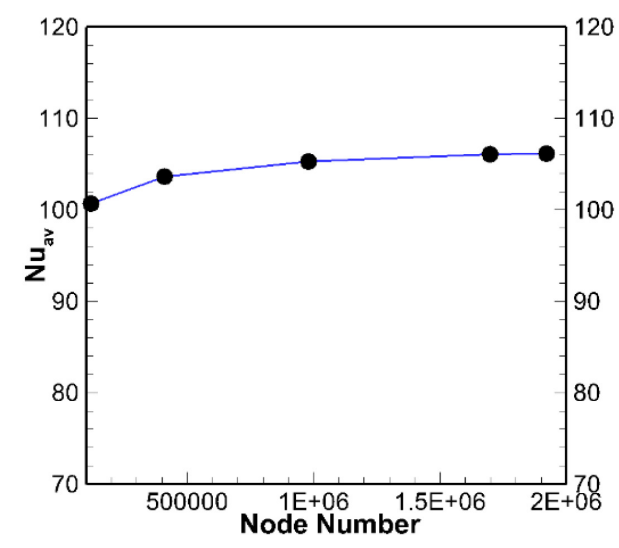

Fig. 6. Grid independence test for $\mathrm{Re}=5000, \mathrm{Ri}=1$ and $\operatorname{Pr}=0.7$.

\section{Results and discussion}

The computational results thus obtained for mixed convection heat transfer of different types of nanofluids inside the cubic enclosure, as discussed in Section 2.1, with moving sidewalls are exhibited in this section. The outcomes are presented in this paper in terms of Nusselt number, isotherm contour, turbulent kinetic energy, root mean square velocity and flow vectors for using both URANS and LES models.

\subsection{The influence of different types of nanofluids}

Herein are three different types of nanofluids, $\mathrm{SiO}_{2}-\mathrm{H}_{2} \mathrm{O}, \mathrm{ZnO}-\mathrm{H}_{2} \mathrm{O}$ and $\mathrm{CuO}-\mathrm{H}_{2} \mathrm{O}$, in comparison to just pure water, have been investigated in this section at volume fraction in the range between 0.00 $0.06, \mathrm{Re}=15000$ and nanoparticle size, $\mathrm{dp}=25 \mathrm{~nm}$ to reveal their performance differences in terms of Nusselt number and turbulent kinetic energy. The local Nusselt numbers on the midlines of the x-y plane for different nanofluids and various volume fractions of nanoparticles are plotted in Fig. 7. Basically, it is observed that the local Nusselt number distributions are symmetric due to the symmetrical boundary conditions. In addition, it is obvious that the Nusselt numbers at the edges of the curves are higher than those in the middle, where the maximum temperature and minimum heat transfer rate yield the lowest local Nusselt number. That is the consequence of higher velocity at the moving walls than at the center of the enclosure. For all values of nanoparticle concentrations, it can be distinctly seen that $\mathrm{SiO}_{2}-\mathrm{H}_{2} \mathrm{O}$ 
has the highest Nusselt number, followed by $\mathrm{ZnO}-\mathrm{H}_{2} \mathrm{O}, \mathrm{CuO}-\mathrm{H}_{2} \mathrm{O}$ and finally the pure water, due to the effects of different thermophysical properties of those fluids. In other words, the velocity of the fluid plays a significant role on the heat transfer coefficient, especially in the case of forced or mixed convection, followed by the conductivity of the fluid and the other properties. Since $\mathrm{SiO}_{2}$ has the lowest density, compared to the other nanoparticles, and higher conductivity than pure water, it can produce the highest Nusselt numbers.

In order to have better understanding of the Nusselt number effects, Table 3 presents the average Nusselt numbers for the four different working fluids. Generally, it can be seen that the $\mathrm{Nu}_{\mathrm{av}}$ increases gradually with increasing the volume fraction for all types of fluids, and obviously the influence of $\mathrm{SiO}_{2}$ $\mathrm{H}_{2} \mathrm{O}$ on the $\mathrm{Nu}_{\mathrm{av}}$ is more pronounced for all four values of volume fraction.

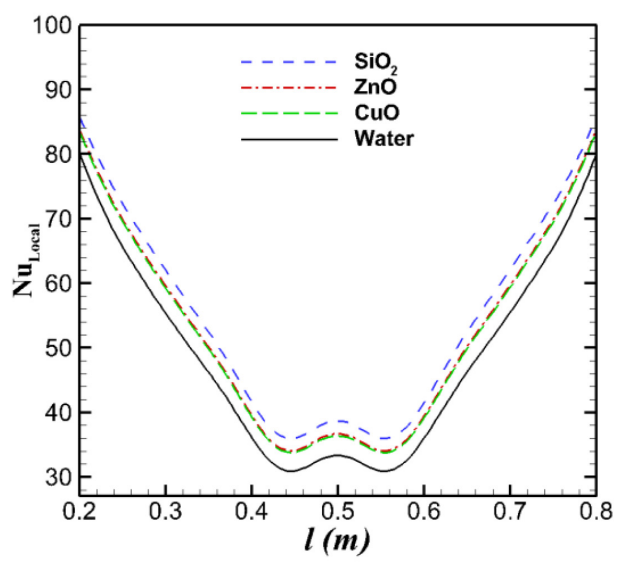

a) $\phi=0.02$

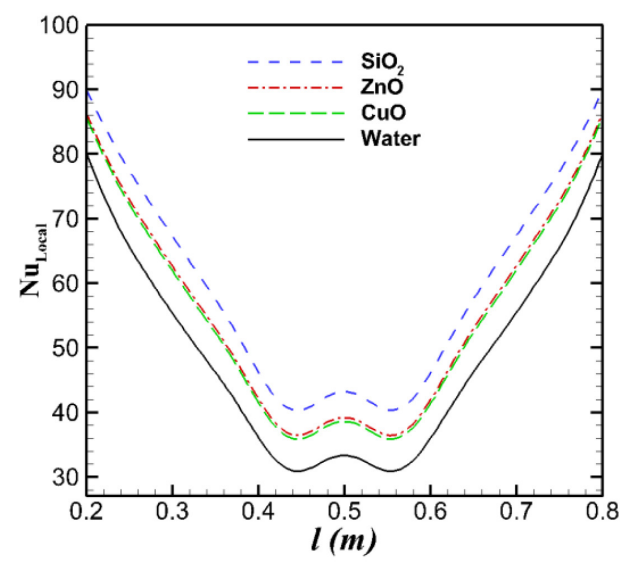

b) $\phi=0.04$

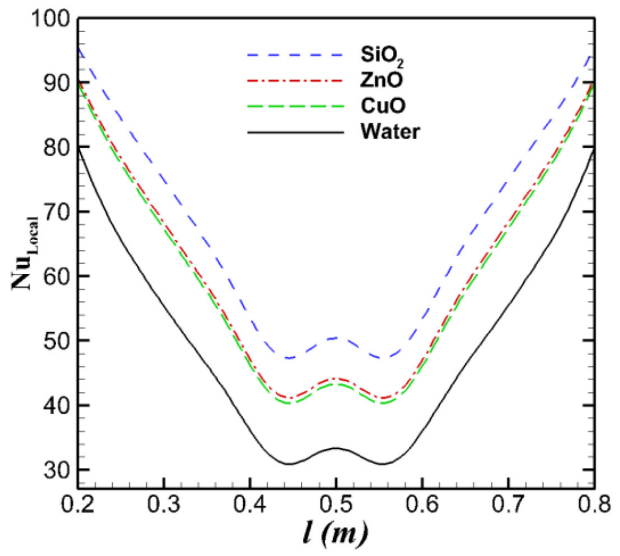

c) $\phi=0.06$

Fig. 7. Local Nusselt number for different nanofluids and volume fraction. 
Table 3

The effects of nanofluid types on Nusselt number at different values of volume fraction.

\begin{tabular}{lllll}
\hline & $\mathrm{H}_{2} \mathrm{O}$ & $\mathrm{CuO}-\mathrm{H}_{2} \mathrm{O}$ & $\mathrm{ZnO}-\mathrm{H}_{2} \mathrm{O}$ & $\mathrm{SiO}_{2}-\mathrm{H}_{2} \mathrm{O}$ \\
\hline$\phi=0.00$ & 49.6786 & 49.6786 & 49.6786 & 49.6786 \\
$N u_{a v}$ Increase & 0.00 & 0.00 & 0.00 & 0.00 \\
\hline$\phi=0.02$ & 49.6786 & 53.11935 & 53.46512 & 55.62882 \\
$N u_{a v}$ Increase & 0.00 & 3.44075 & 3.787 & 5.95022 \\
\hline$\phi=0.04$ & 49.6786 & 55.52771 & 56.16312 & 60.39918 \\
$N u_{a v}$ Increase & 0.00 & 5.84911 & 6.485 & 10.72058 \\
\hline$\phi=0.06$ & 49.6786 & 60.42795 & 61.3118 & 67.49895 \\
$N u_{a v}$ Increase & 0.00 & 10.74935 & 11.633 & 17.82035 \\
\hline
\end{tabular}

The fluctuation kinetic energy profiles at the midlines of the $x-y$ plane are shown in Fig. 8 at constant Reynolds and Grashof numbers for different nanofluids with three concentration values of nanoparticles mixing with the base fluid. Mostly, the turbulence kinetic energies at the centre of the midlines roughly have the same values for all different fluids. In contrast at the sides of the midlines, all show discernible nonlinear increases of the turbulence kinetic energy whether with changing the types of fluids or changing the volume fraction. All these behaviours are due to the nature of the thermophysical properties of the fluids and their effects on the fluid velocities. It can be seen that $\mathrm{SiO}_{2}$ $\mathrm{H}_{2} \mathrm{O}$ displays the highest turbulence kinetic energy, as explained for the Nusselt number distributions. 


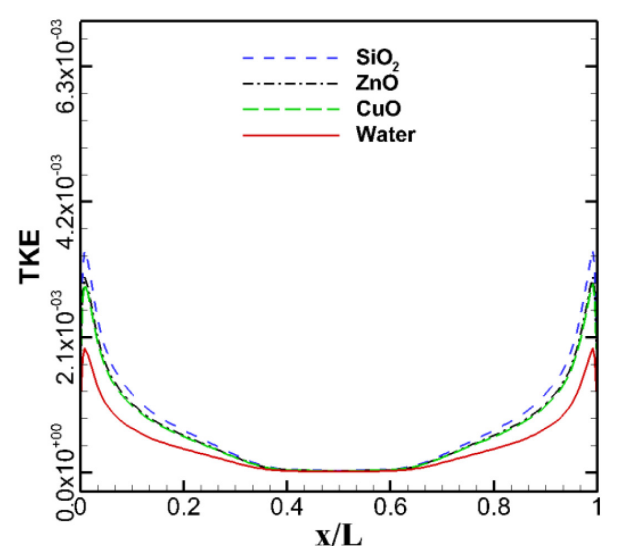

a) $\phi=0.02$

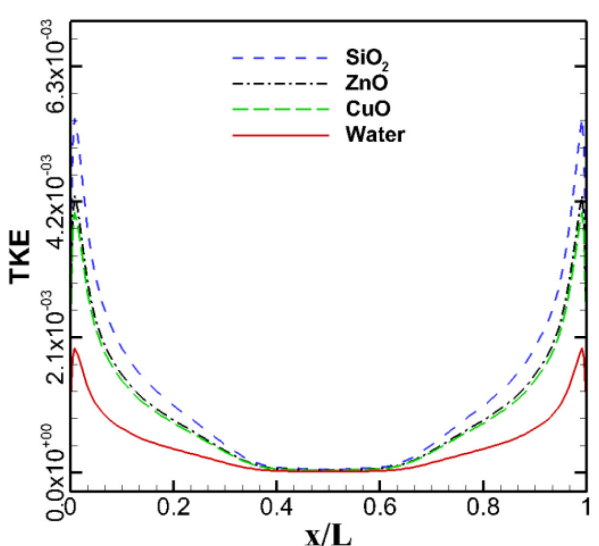

b) $\phi=0.04$

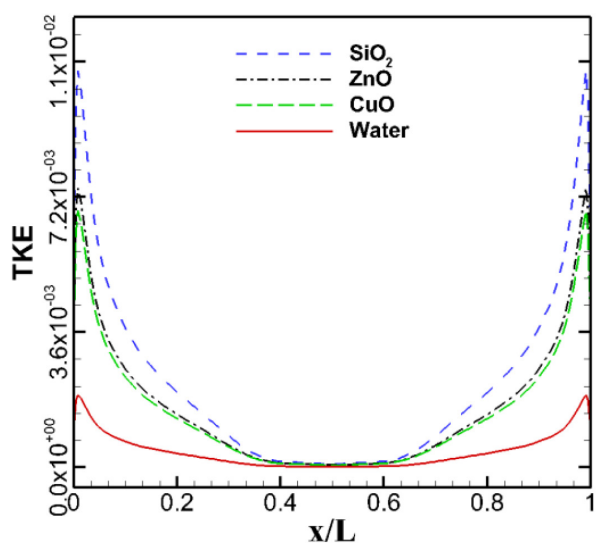

c) $\phi=0.06$

Fig. 8. Turbulence Kinetic Energy for different nanofluids and volume fraction.

\subsection{The influence of different nanoparticle diameters}

The working fluid $\mathrm{SiO}_{2}-\mathrm{H}_{2} \mathrm{O}$ with nanoparticle volume fraction $8 \%$ is selected $\mathrm{x}$ to determine the effects of the nanoparticles size on the heat transfer in term of Nusselt number. Fig. 9 proves that a reduction in the nanoparticles diameter from $85 \mathrm{~nm}$ to $25 \mathrm{~nm}$ has a noticeable influence on the local Nusselt number, because decrementing in nanoparticle size at the same concentration leads to increasing both the surface area of nanoparticles and the Brownian motion velocity of the nanoparticles, which will increase the heat transfer in return. Moreover, it can be seen that a nonlinear relation between the diameter of the nanoparticles and Nusselt number is predicted. 


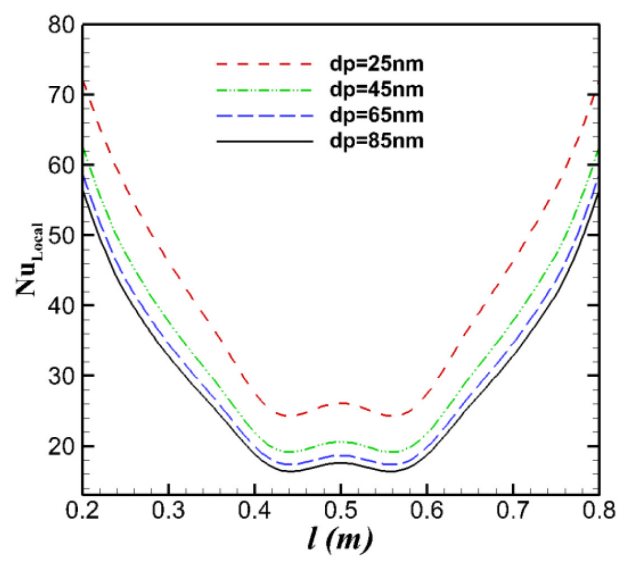

a) $\operatorname{Re}=5000$

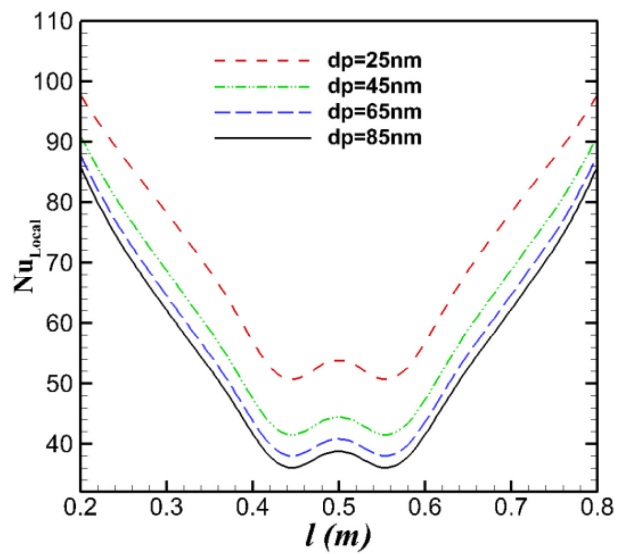

c) $\operatorname{Re}=15000$

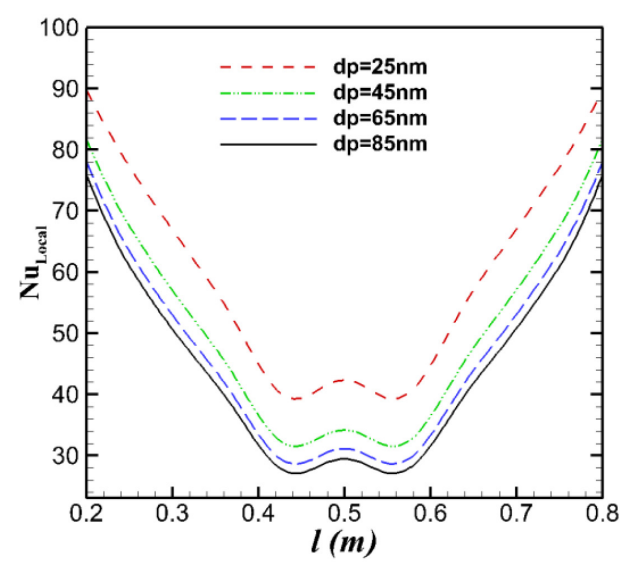

b) $\mathrm{Re}=10000$

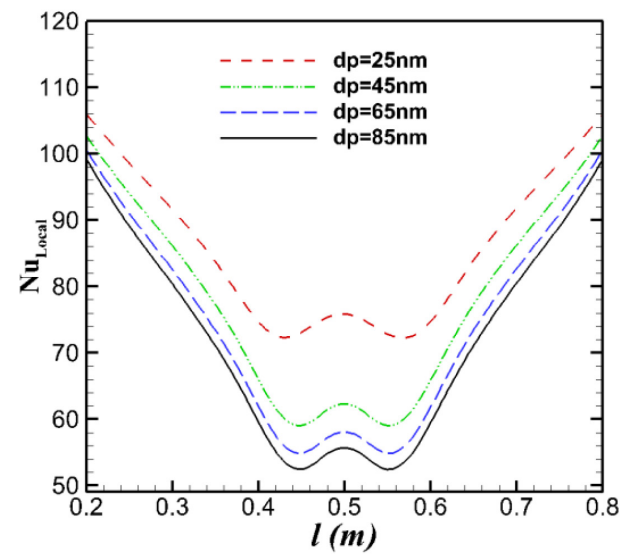

d) $\mathrm{Re}=30000$

Fig. 9. Local Nusselt number distributions for different nanoparticle diameter.

Table 4 displays the effects on the average Nusselt number due to the change in the size of nanoparticles for four Reynolds numbers. It is evident that increasing diameter size leads to the decrease in the $\mathrm{Nu}_{\mathrm{av}}$ numbers, because of the reduction in the surface area of the nanoparticles and fluid velocity.

Table 4

The effects of particle diameter on the Nusselt number at various values of Reynolds number.

\begin{tabular}{lllll}
\hline & $\mathrm{dp}=85 \mathrm{~nm}$ & $\mathrm{dp}=65 \mathrm{~nm}$ & $\mathrm{dp}=45 \mathrm{~nm}$ & $\mathrm{dp}=25 \mathrm{~nm}$ \\
\hline $\mathrm{Re}=5000$ & 29.80632 & 31.32692 & 34.07325 & 41.40925 \\
$N u_{a v}$ Increase & 0.00 & 1.5206 & 2.74633 & 11.60293 \\
\hline $\mathrm{Re}=10000$ & 45.34784 & 47.36077 & 50.89725 & 59.77192 \\
$N u_{a v}$ Increase & 0.00 & 2.01293 & 5.54941 & 14.42408 \\
\hline $\mathrm{Re}=15000$ & 55.70584 & 57.88258 & 61.64008 & 70.70755 \\
$N u_{a v}$ Increase & 0.00 & 2.17674 & 5.93424 & 15.00171 \\
\hline $\mathrm{Re}=30000$ & 72.70905 & 74.85098 & 78.45065 & 86.21242 \\
$N u_{a v}$ Increase & 0.00 & 2.14193 & 5.7416 & 13.50337 \\
\hline
\end{tabular}


Decreasing the nanoparticle diameter provides higher turbulent kinetic energy, as observed from Fig. 10, as well as, at all values of the Reynolds number the diameter of $25 \mathrm{~nm}$ shows the highest fluctuation turbulent energy. That is due to the increment in both the velocity and conductivity of the working fluid caused by the diameter reduction.

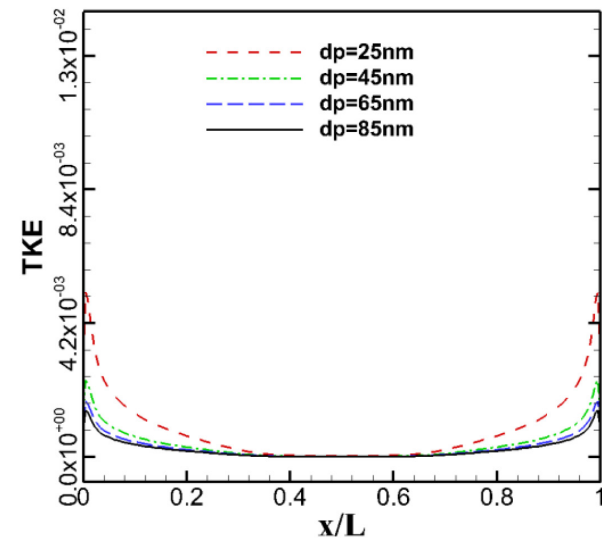

a) $\operatorname{Re}=5000$

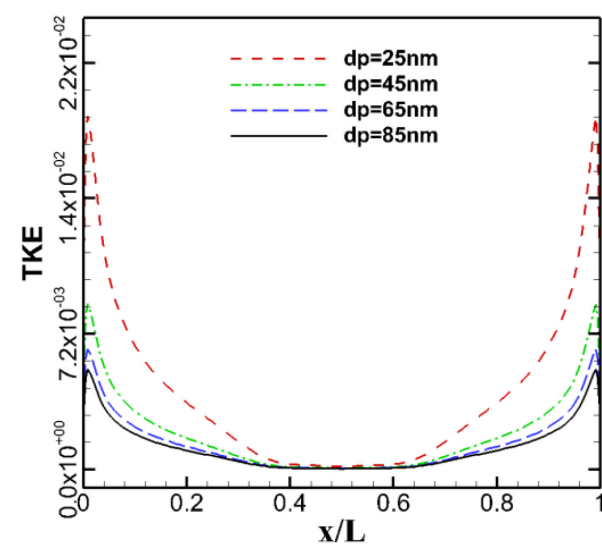

c) $\operatorname{Re}=15000$

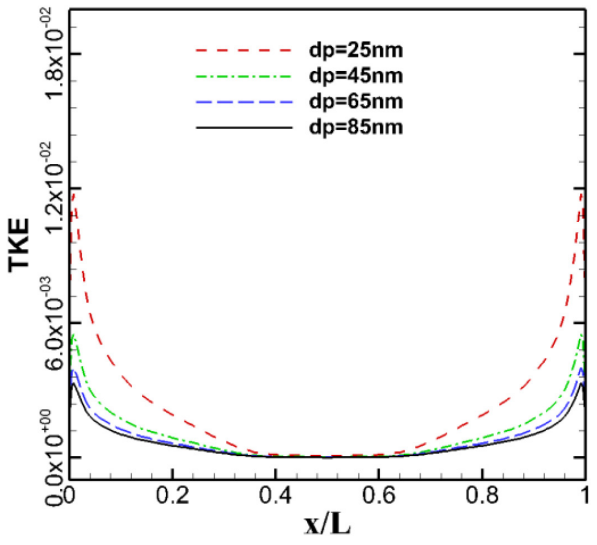

b) $\operatorname{Re}=10000$

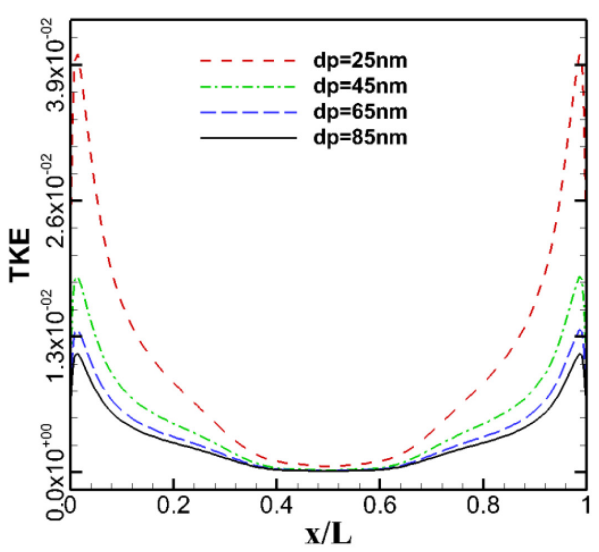

d) $\operatorname{Re}=30000$

Fig. 10. Turbulence kinetic energy distributions for different nanoparticle sizes.

\subsection{The influence of volume fraction}

As shown earlier in this study the nanofluid $\mathrm{SiO}_{2}-\mathrm{H}_{2} \mathrm{O}$ provides the best heat transfer coefficient among other fluids, so investigations of various solid volume fractions, $\phi=0.00,0.02,0.04,0.06$ and 0.08, of $\mathrm{SiO}_{2}-\mathrm{H}_{2} \mathrm{O}$ for different high values of Reynolds number, $\mathrm{Re}=5000,10000,15000$ and 30000, have been conducted. The distribution of the local Nusselt number on the midlines of the bottom wall at $\mathrm{z}=$ 0.5 is plotted in Fig. 11. The curves show that growing in volume fraction with the same Reynolds number enhances the Nusselt number due to the higher thermal conductivity of nanofluids than the pure water. The sensitivity of the Nusselt number to the volume fraction increases with increasing the Reynolds number. Moreover, at constant value of volume fraction of $\mathrm{SiO}_{2}$, the increment in the Reynolds 
number leads to a discernible enhancement in the Nusselt number, which come from the increase in the fluid velocity and from changing in the thermal properties.

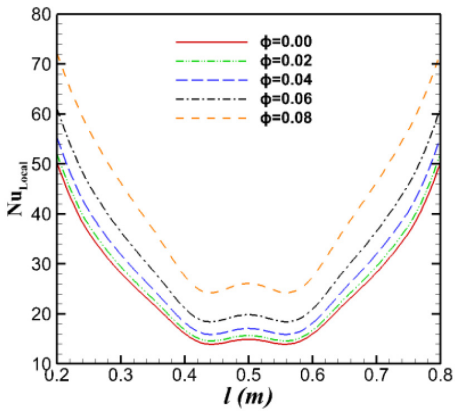

a) $\operatorname{Re}=5000$

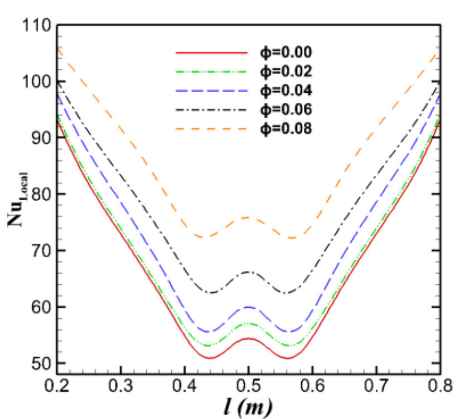

d) $\operatorname{Re}=30000$

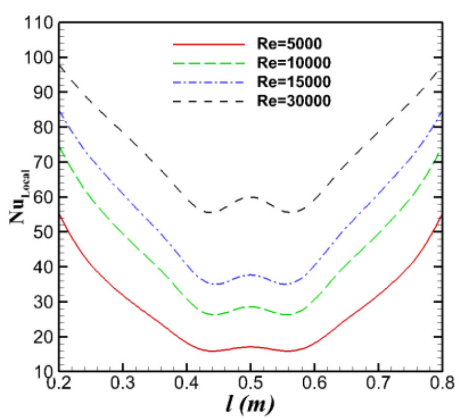

g) $\phi=0.04$

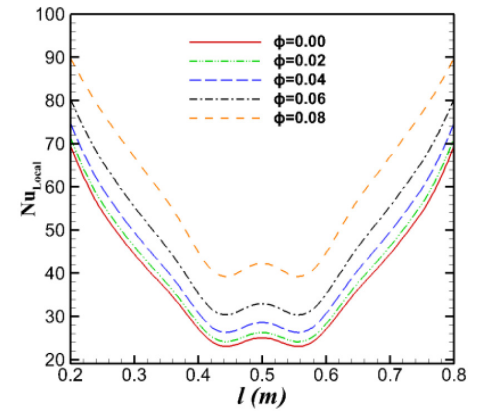

b) $\operatorname{Re}=10000$

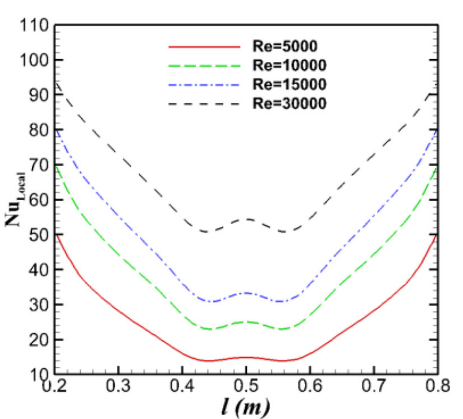

e) $\phi=0.00$

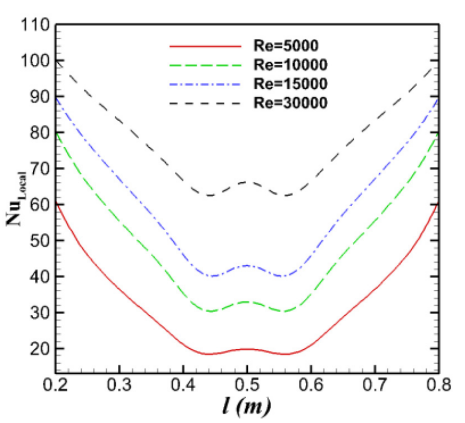

h) $\phi=0.06$

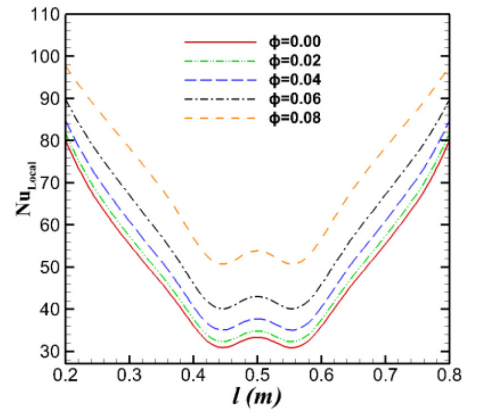

c) $\operatorname{Re}=15000$

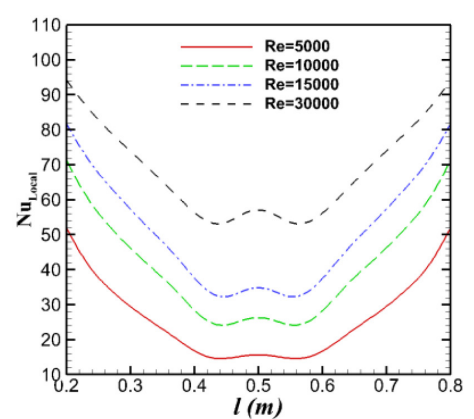

f) $\phi=0.02$

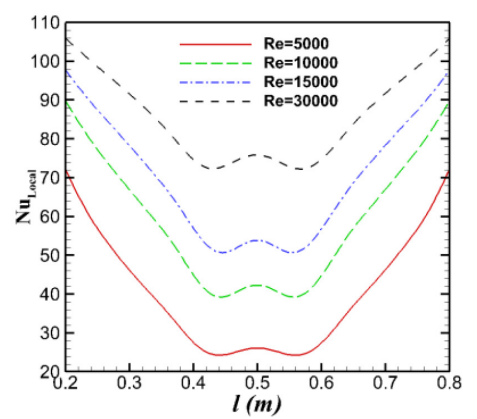

i) $\phi=0.08$

Fig. 11. Local Nusselt number distributions for different volume fraction.

Table 5 shows the average Nusselt number comparison among five different values of volume fraction in the range $0.00-0.08$ and for four different values of Reynolds number. Generally, the $\mathrm{Nu}_{\mathrm{av}}$ increases gradually with increasing volume fraction for all Reynolds number values, and obviously the influences of the highest volume fraction and Reynolds number on the $\mathrm{Nu}_{\mathrm{av}}$ are more discernible. 
Table 5

The effects of volume fraction on Nusselt number at various values of Reynolds number.

\begin{tabular}{llllll}
\hline & $\phi=0.00$ & $\phi=0.02$ & $\phi=0.04$ & $\phi=0.06$ & $\phi=0.08$ \\
\hline $\mathrm{Re}=5000$ & 25.80345 & 26.8966 & 29.02242 & 32.98182 & 41.40925 \\
$N u_{a v}$ Increase & 0.00 & 1.09315 & 3.21897 & 7.17837 & 15.6058 \\
\hline $\mathrm{Re}=10000$ & 39.9006 & 41.42454 & 44.32331 & 49.52177 & 59.77192 \\
$N u_{a v}$ Increase & 0.00 & 1.52394 & 4.42271 & 9.62117 & 19.87132 \\
\hline $\mathrm{Re}=15000$ & 49.6786 & 51.38977 & 54.5933 & 60.19113 & 70.70755 \\
$N u_{\text {av }}$ Increase & 0.00 & 1.71117 & 4.9147 & 10.51253 & 21.02895 \\
\hline $\mathrm{Re}=30000$ & 67.46731 & 68.89562 & 72.63527 & 77.91314 & 86.21242 \\
$N u_{a v}$ Increase & 0.00 & 1.42831 & 5.16796 & 10.44583 & 18.74511 \\
\hline
\end{tabular}

The turbulent kinetic energy distributions for various volume fractions and different values of Reynolds number have been studied here. Fig. 12 displays the turbulent kinetic energy curves on the midlines of the bottom wall of the cavity at several Reynolds numbers and nanoparticle concentrations, respectively. It can be seen clearly that the responses of the turbulent kinetic energy to the changes of volume fraction are much less than to the changes of Reynolds number, because of the significant increase in the flow velocity through increasing Reynolds number.

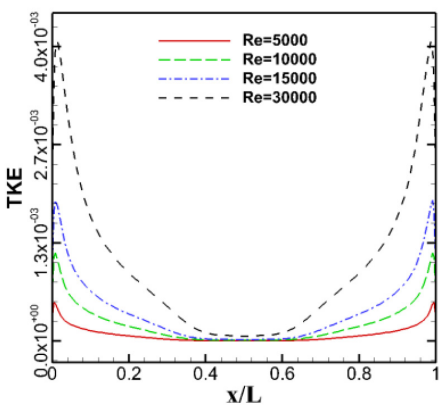

a) $\phi=0.00$

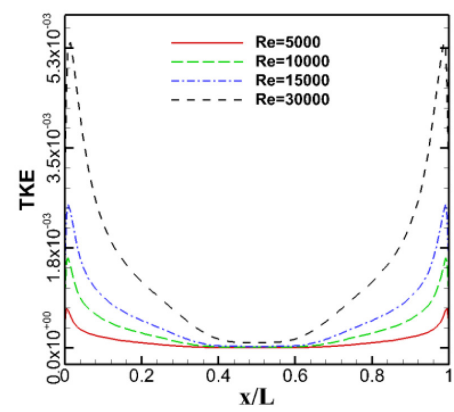

b) $\phi=0.02$

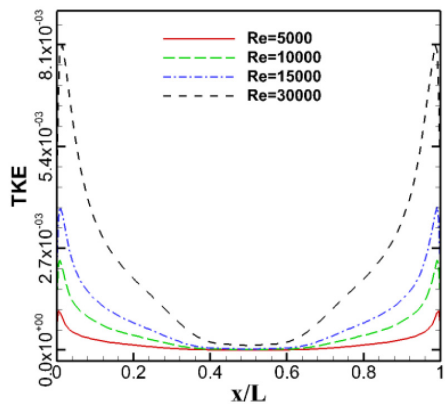

c) $\phi=0.04$

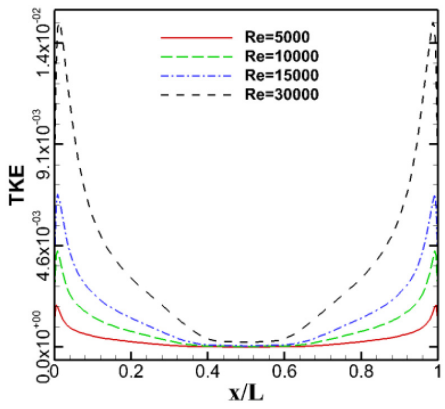

d) $\phi=0.06$

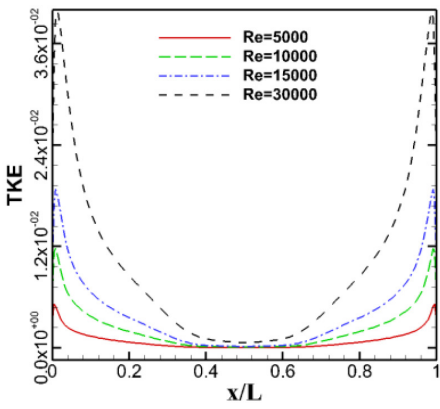

e) $\phi=0.08$

Fig. 12. Turbulence kinetic energy distributions for different Reynolds number.

Fig. 13a-c presents the dimensionless root mean square velocity $\mathrm{U}_{\text {rms }}$ on $\mathrm{x}$-axis of the centrelines of the symmetric plane. As it can be seen, for any Reynolds number, $U_{\mathrm{rms}}$ in all different values of volume fraction is higher at the moving walls than that at the centre of the enclosure and much close to 
the pure water. $U_{\mathrm{rms}}$ increases slightly by adding more nanoparticles and the increment ratio increases gradually by increasing the nanoparticles volume fraction. By looking from another angle of the effects of nanofluids on the fluctuation velocity (Fig. 13d-h), it can be observed that the differences in $U_{\text {rms }}$ values of using three different Reynolds numbers are roughly the same. As well as, the increase ratio of different concentrations of nanoparticles is roughly constant. The main reason of this increase in fluctuation velocity comes from the reduction of the dynamic viscosity in the working fluid by adding more nanoparticles, which causes the increase in the velocity accordingly.

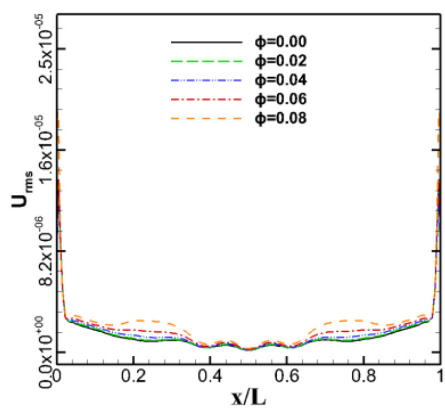

a) $\operatorname{Re}=5000$

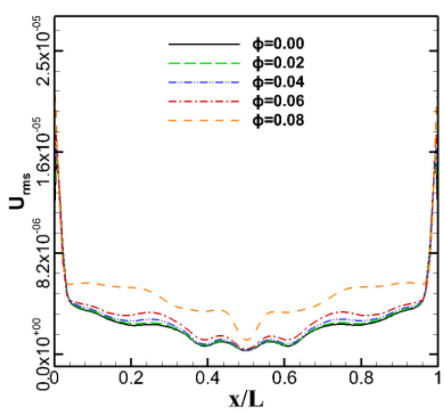

b) $\operatorname{Re}=10000$

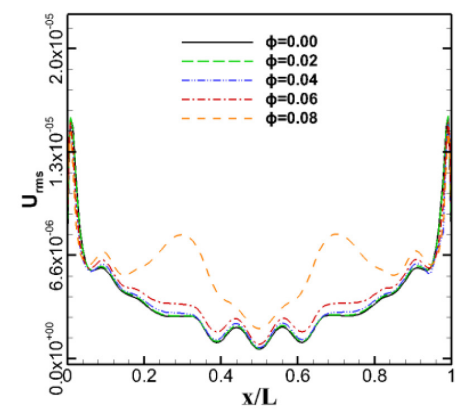

c) $\operatorname{Re}=15000$

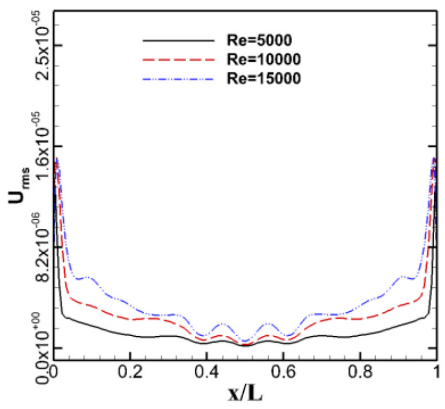

d) $\phi=0.00$

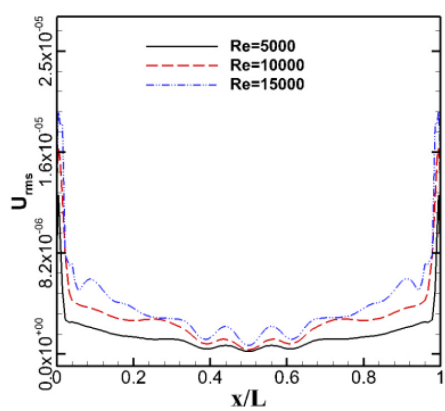

f) $\phi=0.04$

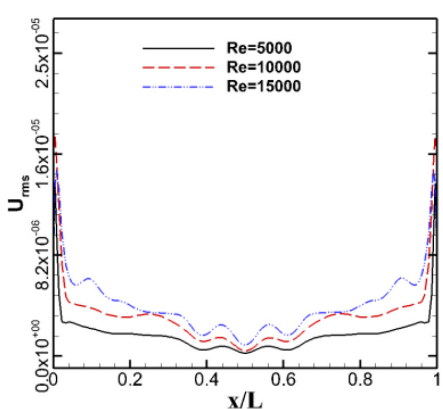

g) $\phi=0.06$

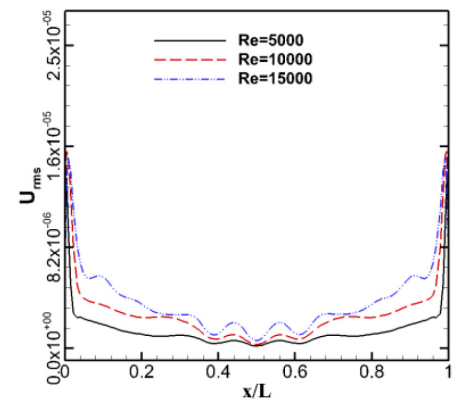

e) $\phi=0.02$

Fig. 13. Root mean square velocity on x-axis at different Reynolds numbers and volume fraction.

The isothermal contour comparisons between the pure water and the nanofluid of $\mathrm{SiO}_{2}$ with various volume fractions, $\phi=0.00-0.08$, and at constant Grashof number and three values of Reynolds 
number, $\operatorname{Re}=5000,10000$ and 15000, have been made as shown in Fig. 14. In general, at different values of volume fraction and Reynolds number, it can be observed that the thermal conduction is higher at the heat source area than thermal convection, unlike at other areas of the walls. For all Reynolds number values, it can be observed that the conduction effect increases with the increasing nanoparticles concentration. This indicates that the role of conduction increases in the cavity with increasing conductivity of the working fluid due to increasing in volume fraction. In addition, it is obvious that the flow and temperature patterns are affected by the participation of nanoparticles in the working fluid, which means mixing nanoparticles with pure water causes a reduction in the strength of the flow field. The reduction is more pronounced at the highest volume fraction, $\phi=0.08$, and the lowest Reynolds number, $\operatorname{Re}=5000$, where conduction dominates. However, the reduction is only slightly for the highest Reynolds number, $\mathrm{Re}=30000$, where the forced convection is dominant. An enhancement of heat transfer performance is observed by involving nanoparticles as can be seen from the reduction of the maximum dimensionless temperature.

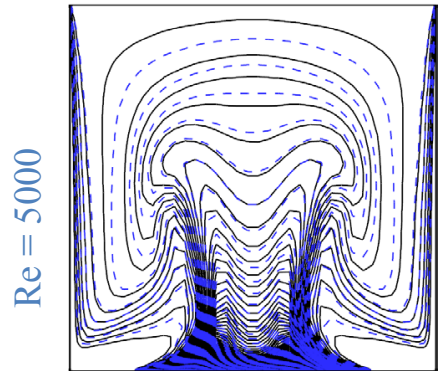

a) $\phi=0.02$

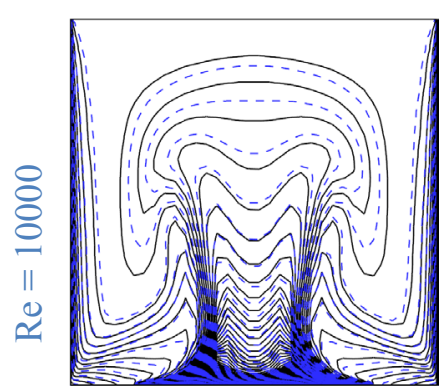

a) $\phi=0.02$

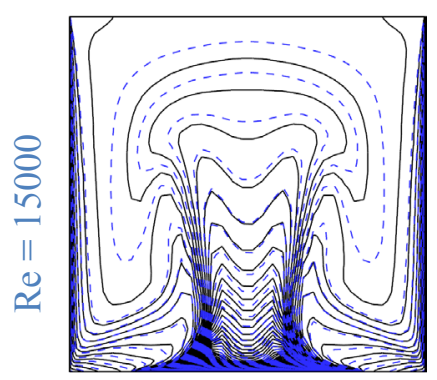

a) $\phi=0.02$

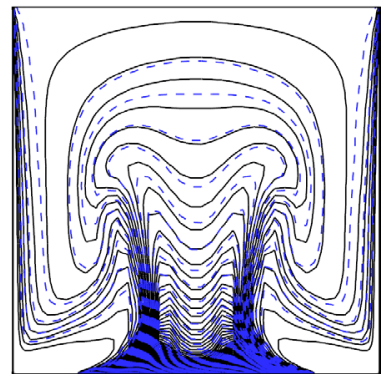

b) $\phi=0.04$

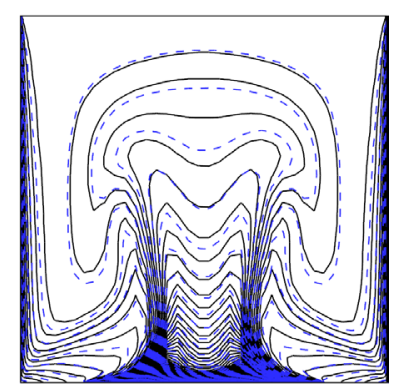

b) $\phi=0.04$

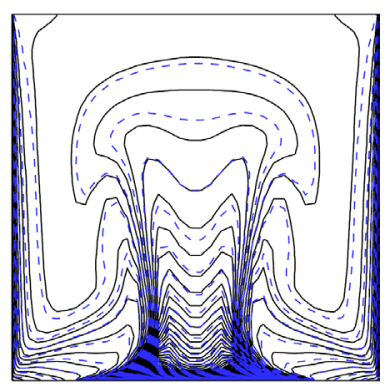

$\phi=0.04$

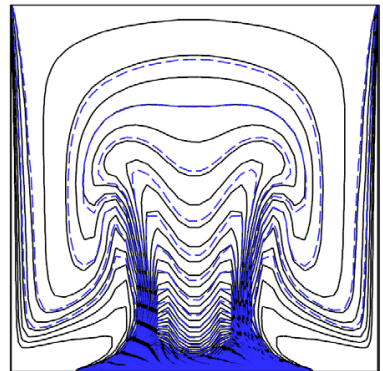

c) $\phi=0.06$

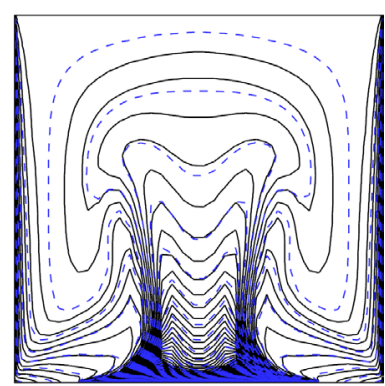

c) $\phi=0.06$

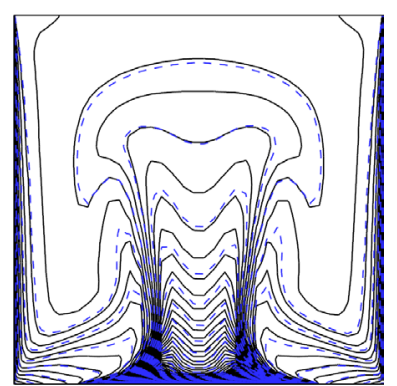

b) $\phi=0.06$

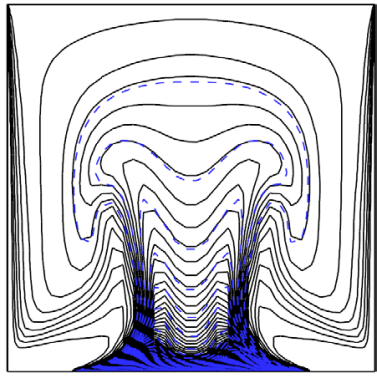

d) $\phi=0.08$

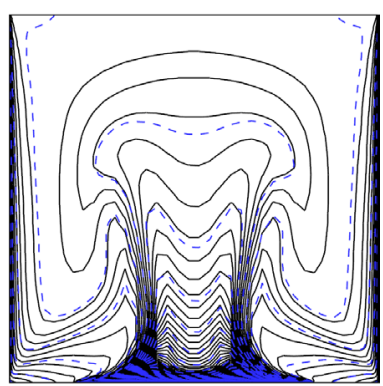

d) $\phi=0.08$

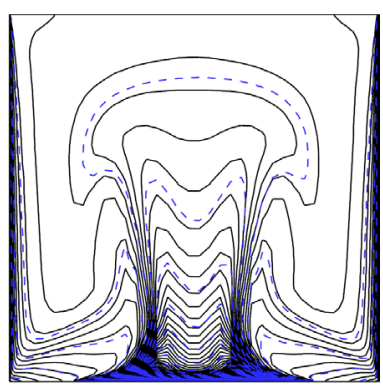

c) $\phi=0.08$

Fig. 14. Isotherm comparisons for $\mathrm{SiO}_{2}-\mathrm{H}_{2} \mathrm{O}$ (---) with pure water(-) at various values of Reynolds number and volume fraction. 


\subsection{Isotherm contours and velocity vectors by LES}

Isotherms and vectors of the $x-y$ plane located at the midway of the $z$-axis are shown in Fig. 15 by using the LES model at $\mathrm{Re}=10000$ to display the effects of nanoparticles concentration on the heat and flow patterns. Basically, it can be observed that the plane is divided into two sympatric halves and in almost symmetrical shape. In other words, it can be seen that the increment in volume fraction causes changing in the details of flow characteristics. As well as, it can be figured out that the turbulence effect is increasing with adding more nanoparticles, because of the changes in fluid thermal properties of the working fluid apart from the fluid velocity change.

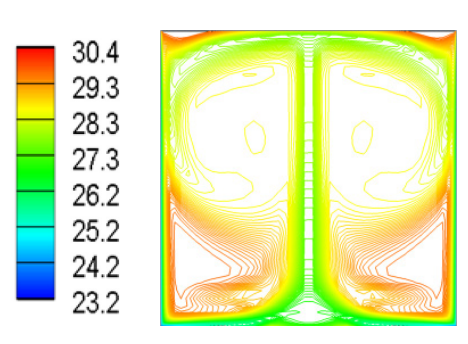

a) $\phi=0.00$

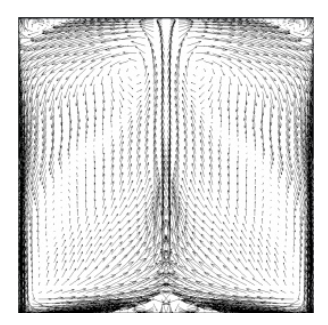

b) $\phi=0.02$

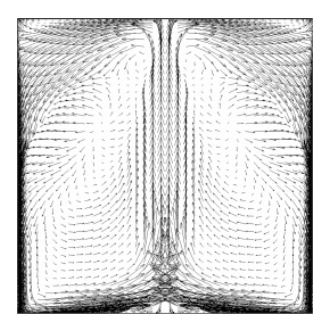

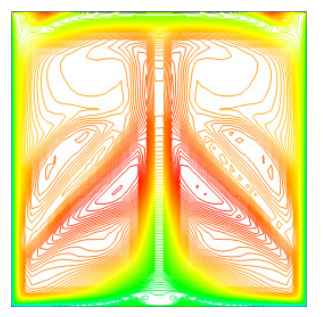

c) $\phi=0.04$

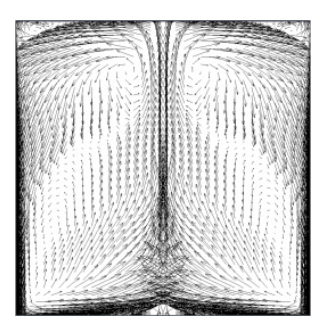

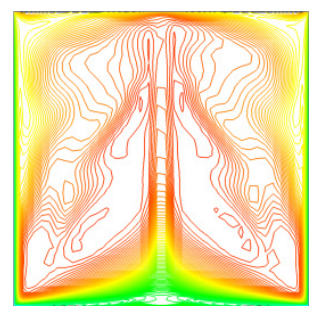

d) $\phi=0.06$

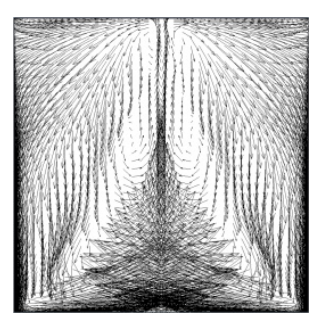

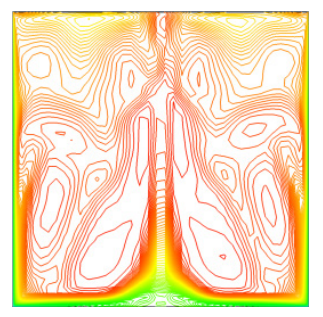

e) $\phi=0.08$

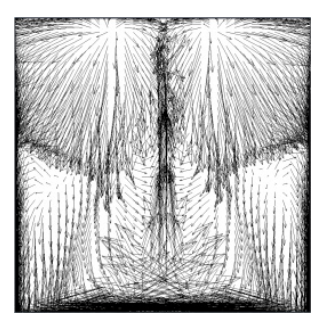

Fig. 15. Isotherms and vectors for different volume fractions of the $x-y$ plane at the middle of $z$-axis, at $R e=10000$, by using LES.

\subsection{Average Nusselt number comparison between URANS and LES}

The comparison results of the two turbulent methods in term of average Nusselt number for five different values of volume fraction are visualised in Fig. 16. In general, it shows that increasing in the nanoparticle volume fraction will enhance the average Nusselt number inside the cavity by using both URANS and LES methods for selected Reynolds numbers, $R e=5000$ and10000, with constant Grashof number. Furthermore, it can be seen that the URANS model predicts slightly lower average Nusselt numbers for all volume fraction values compared to the ones derived by involving the LES model, which reflects the nature of the turbulence models. 


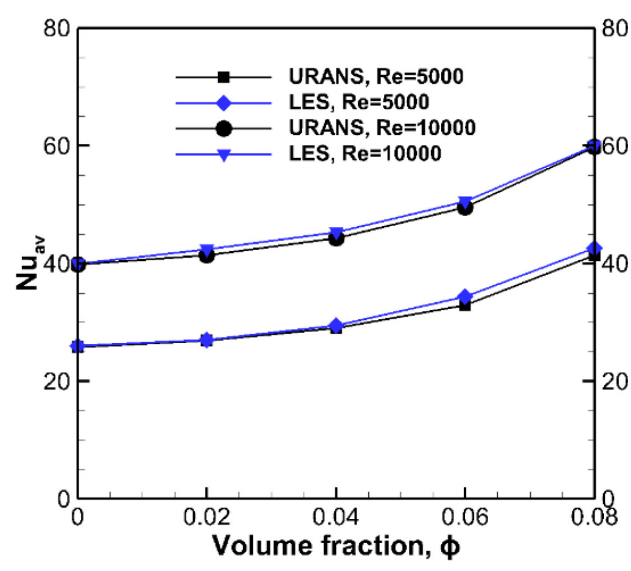

Fig. 16. Comparison of average Nusselt numbers for different Reynolds numbers and volume fraction.

\section{Conclusion}

A numerical investigation of turbulent mixed convection heat transfer for different types of nanofluids in comparison to the conventional fluid (water) inside a double lid-driven enclosure has been carried out by utilizing both URANS and LES methods. The well-known wo-phase mixture model was used to simulate the nanofluids mixtures. Some selected nanofluid types, nanoparticles' concentration and nanoparticles' diameter size were studied at various high values of Reynolds number. These parameters were evaluated in terms of Nusselt number, turbulent kinetic energy, root mean square velocity and isothermal contours. The discernible observations in this research have attempted to conclude the following points:

- For the given fluid types and Grashof number values, significant enhancement on local and average Nusselt numbers can be achieved due to increasing in Reynolds number.

- Adding nanoparticles to the base fluid provides higher heat transfer coefficient and turbulent kinetic energy compared to the conventional fluid, and $\mathrm{SiO}_{2}$ nanoparticles show the best heat transfer rate followed by $\mathrm{ZnO}$ and $\mathrm{CuO}$.

- At any values of Reynolds number, discernible augmentation in the Nusselt number and turbulent kinetic energy has been observed by either adding more nanoparticles to the base fluid (higher volume fraction) or increasing the surface area of the nanoparticles (lower nanoparticles diameter).

- It has been shown that flow and temperature patterns can be affected by the presence of nanoparticles, and the influence on patterns increases more significantly by either decreasing the Reynolds number or increasing the nanoparticle volume fraction.

- Noticeable differences in the flow structures and heat distributions inside the cavity have been captured by using the LES method for different nanoparticle concentration, in contrast to the RANS model, even the difference in the overall average Nusselt numbers is small between the two methods.

\section{Acknowledgements}

The authors would like to thank the Ministry of Higher Education and Scientific Research of Iraq for the financial support of the project. 


\section{References}

[1] G. Guo, M.A. Sharif, Mixed convection in rectangular cavities at various aspect ratios with moving isothermal sidewalls and constant flux heat source on the bottom wall, International journal of thermal sciences, 43(5) (2004) 465-475.

[2] E. Abu-Nada, A.J. Chamkha, Mixed convection flow of a nanofluid in a lid-driven cavity with a wavy wall, International Communications in Heat and Mass Transfer, 57 (2014) 36-47.

[3] M. Goodarzi, M. Safaei, K. Vafai, G. Ahmadi, M. Dahari, S. Kazi, N. Jomhari, Investigation of nanofluid mixed convection in a shallow cavity using a two-phase mixture model, International Journal of Thermal Sciences, 75 (2014) 204-220.

[4] A.K. Kareem, H. Mohammed, A.K. Hussein, S. Gao, Numerical investigation of mixed convection heat transfer of nanofluids in a lid-driven trapezoidal cavity, International Communications in Heat and Mass Transfer, 77 (2016) 195-205.

[5] M. Billah, M. Rahman, M. Razzak, R. Saidur, S. Mekhilef, Unsteady buoyancy-driven heat transfer enhancement of nanofluids in an inclined triangular enclosure, International Communications in Heat and Mass Transfer, 49 (2013) 115-127.

[6] E. Abu-Nada, A.J. Chamkha, Mixed convection flow in a lid-driven inclined square enclosure filled with a nanofluid, European Journal of Mechanics-B/Fluids, 29(6) (2010) 472482.

[7] B. Ghasemi, S. Aminossadati, Mixed convection in a lid-driven triangular enclosure filled with nanofluids, International Communications in Heat and Mass Transfer, 37(8) (2010) 11421148.

[8] M. Alinia, D. Ganji, M. Gorji-Bandpy, Numerical study of mixed convection in an inclined two sided lid driven cavity filled with nanofluid using two-phase mixture model, International Communications in Heat and Mass Transfer, 38(10) (2011) 1428-1435.

[9] A.K. Kareem, S. Gao, A.Q. Ahmed, Unsteady simulations of mixed convection heat transfer in a 3D closed lid-driven cavity, International Journal of Heat and Mass Transfer, 100 (2016) 121-130.

[10] O.A. Yang, Wen-Jei, Mixed convection in cavities with a locally heated lower wall and moving sidewalls, Numerical Heat Transfer: Part A: Applications, 37(7) (2000) 695-710.

[11] O. Aydm, Aiding and opposing mechanisms of mixed convection in a shear-and buoyancydriven cavity, International communications in heat and mass transfer, 26(7) (1999) 1019-1028. [12] A. Mohamad, R. Viskanta, Flow and heat transfer in a lid-driven cavity filled with a stably stratified fluid, Applied mathematical modelling, 19(8) (1995) 465-472.

[13] N. Ouertatani, N.B. Cheikh, B.B. Beya, T. Lili, A. Campo, Mixed convection in a double lid-driven cubic cavity, International Journal of Thermal Sciences, 48(7) (2009) 1265-1272.

[14] M. Mamun, T. Tanim, M. Rahman, R. Saidur, S. Nagata, Mixed convection analysis in trapezoidal cavity with a moving lid, International Journal of Mechanical and Materials Engineering, 5(1) (2010) 18-28.

[15] A. FLUENT, 15.0 Theory Guide, Ansys Inc, 5 (2013).

[16] P. Huang, J. Bardina, T. Coakley, Turbulence Modeling Validation, Testing, and Development, NASA Technical Memorandum, 110446 (1997).

[17] J. Smagorinsky, General circulation experiments with the primitive equations: I. the basic experiment*, Monthly weather review, 91(3) (1963) 99-164.

[18] H. Mohammed, A. Al-Shamani, J. Sheriff, Thermal and hydraulic characteristics of turbulent nanofluids flow in a rib-groove channel, International Communications in Heat and Mass Transfer, 39(10) (2012) 1584-1594.

[19] B. Ghasemi, S. Aminossadati, Brownian motion of nanoparticles in a triangular enclosure with natural convection, International Journal of Thermal Sciences, 49(6) (2010) 931-940. 
[20] R.S. Vajjha, D.K. Das, D.P. Kulkarni, Development of new correlations for convective heat transfer and friction factor in turbulent regime for nanofluids, International Journal of Heat and Mass Transfer, 53(21) (2010) 4607-4618.

[21] R.S. Vajjha, D.K. Das, Specific heat measurement of three nanofluids and development of new correlations, Journal of heat transfer, 131(7) (2009) 071601.

[22] B.C. Sahoo, Measurement of rheological and thermal properties and the freeze-thaw characteristics of nanofluids, 2008.

[23] M. Corcione, Heat transfer features of buoyancy-driven nanofluids inside rectangular enclosures differentially heated at the sidewalls, International Journal of Thermal Sciences, 49(9) (2010) 1536-1546.

[24] M. Sharif, Laminar mixed convection in shallow inclined driven cavities with hot moving lid on top and cooled from bottom, Applied thermal engineering, 27(5) (2007) 1036-1042.

[25] C.-L. Chen, C.-H. Cheng, Experimental and numerical study of mixed convection and flow pattern in a lid-driven arc-shape cavity, Heat and mass transfer, 41(1) (2004) 58-66.

[26] A.K. Prasad, J.R. Koseff, Reynolds number and end-wall effects on a lid-driven cavity flow, Physics of Fluids A: Fluid Dynamics (1989-1993), 1(2) (1989) 208-218. 